\title{
Memória e história na sala de aula: \\ a experiência do indivíduo
}

Sueli Soares dos Santos Batista

Professora da FATEC-Jundiaí

Pesquisadora do Núcleo de Estudos sobre Tecnologia e Sociedade (NETS)

\section{Resumo}

O presente trabalho tem o objetivo de pensar as relações entre memória e história na sala de aula e como é possível articular o ensino de história com a experiência do indivíduo. Inicialmente, apresenta-se uma discussão a partir de um referencial teórico que problematiza essas relações do ponto de vista da formação do indivíduo num sentido amplo, o que não exclui, obviamente, as reflexões educacionais. Num segundo momento, demonstra-se como a questão problematizada aparece no caderno de História dos PCNs.

Palavras-chave: Memória; História; PCNs.

\begin{abstract}
This article has the objective to present a meditation about the connections between memory and history in the classroom, and how it becomes possible to articulate the teaching of History with the individual experience. Initially, a discussion is introduced from a theorist reference, which calls in question these relations through the point of view of the individual's formation, widely comprehended, what obviously doesn't exclude the educational reflections. In the second part, it is demonstrated how the questioned point appears in the PCNs' History Notebook.
\end{abstract}

Keywords: Memory; History; PCNs. 
Não é da conservação do passado, mas de resgatar a esperança passada que se trata.

Horkheimer e Adorno,

Dialética do Esclarecimento

$\mathrm{U}$

ma relação crítica com o passado é incompatível com a desmemoriação no mundo administrado. $\mathrm{O}$ rompimento com a tradição não é tão somente a possibilidade de realizar as potencialidades humanas como consideravam já os renascentistas frente ao pensamento medieval. Com o esquecimento também começa a entrada na desumanidade: o sofrimento acumulado é esquecido. Octavio Paz expressa, belamente, essa idéia que vai ao encontro da filosofia da história presente tanto em Walter Benjamin, como em Freud:

Vivemos entre o mito e a negação, idolatramos certos períodos, nos esquecemos de outros. Esses esquecimentos são significativos; existe uma censura histórica como há uma censura psíquica. Nossa história é um texto cheio de trechos escritos com tinta negra e outros escritos com tinta invisível. Parágrafos repletos de signos de admiração seguidos de parágrafos riscados. (Paz, 1998, p. 27)

Daí a necessidade de despertar no passado as "centelhas da esperança”, procurando resgatar o que não se realizou (Horkheimer e Adorno, 1985, p. 15). Exorcizar os motivos poderosos que deram forma ao esquecimento como lembranças encobridoras é tarefa de uma humanidade redimida ${ }^{1}$. Algumas frestas, no entanto, são possíveis por meio de outros sistemas diversos da consciência. Para localizá-las, precisamos também olhar para a história, para as tradições não só como fruto da lembrança, mas sobretudo do esquecimento. A memória assume o papel, então, de conservar esses conteúdos recalcados. A lembrança é a tentativa incansável de destruí-los. Proust,

1 O termo "lembranças encobridoras" aparece pela primeira vez nas obras de Freud em 1899 , sendo definidas como aquelas que devem seu valor como lembrança não a seu próprio conteúdo, mas às relações existentes entre esse conteúdo e algum outro que tenha sido suprimido, recalcado. (Vol. III, p. 302). Literalmente, lembranças que encobrem algo que precisa ser esquecido. As lembranças de infância, exemplar nesse aspecto, não emergem na consciência, são formadas pela consciência em momentos posteriores. A precisão histórica não faz parte de suas prerrogativas, o que não quer dizer que delas não possa ser retirado algum conteúdo de verdade.

(C) Filosofia e Educação (Online), ISSN 1984-9605 - Revista Digital do Paideia 
ao tratar da "memória involuntária", ressalta as falas do corpo. Por exemplo, como repentinamente as imagens mnemônicas nele contidas penetram no consciente a partir de determinada posição que uma coxa, um braço ou uma omoplata assumem, "tal como o fizeram uma vez no passado" (apud Benjamin, 1994, pp. 108 e ss.). O passado se revelaria, portanto, mais por meio de um objeto qualquer, de uma imagem, de uma imagem histórica.

Essa perspectiva que rompe com a continuidade histórica, Benjamin encontra em Freud, em Proust e também em Bergson. Comentando Matière e Mémoire, Benjamin aponta para o fato de a experiência ser matéria da tradição ao se formar menos com dados isolados e rigorosamente fixados que com dados inconscientes que afluem à memória (idem, p. 105).

Mas somos herdeiros da tradição iluminista que baniu a tradição para o terreno do pré-científico, do mito, da ausência de crítica. A modernidade não tolera o tradicionalismo ou o que tem "mais de trinta anos". No mundo dos objetos e pessoas descartáveis, tradição e tradicionalismos são dissonâncias. Mas também estamos inseridos no plano da racionalidade do mito, que retorna sempre, contrariando as explicações que separam radicalmente mito e racionalidade, natureza e história, magia e técnica, pensamento e corpo. Quando a sociedade feudal foi considerada tradicionalista e isso significava irracional, a tradição foi colocada em contradição com a racionalidade, apesar de essa racionalidade naquela tradição se formar. Nesse sentido, como colocar a tradição em oposição à racionalidade, já que a racionalidade também é formada na tradição?

Para nos aproximarmos do que seria a dinâmica da tradição é necessário avaliarmos sua razão e sua desrazão, o processo histórico que a determina e as determinações históricas que ela ultrapassa, o seu teor de mais repressão indissociável da mais valia e, ao mesmo tempo, os caminhos emancipatórios que desencadeia. $\mathrm{O}$ que permanece não coincide necessariamente e sempre com a lógica da história, da dominação ou da razão, embora sem esses referenciais, facilmente, caímos no encanto de legitimar, incondicionalmente, a longa duração na história. Poder pensar a dialética do esclarecimento é também pensar a dialética da tradição, da relação entre o arcaico e o novo. 
Assim é que o horror ao "sempre o mesmo" e ao estereotipado como "antiquado", a busca desenfreada pelo novo, revelam as condições objetivas engendradas pela burguesia: superação do mundo medieval com sua base tradicionalista, fetichização da mercadoria que sustenta as relações sociais e de produção, processo inflacionário em que tudo perde seu valor numa velocidade assustadora, esvaziando o sentido de "herança", seja espiritual, seja material. A nada recente idiossincrasia frente à tradição mostra o quanto ela é incompatível com a sociedade burguesa. O que não é aqui e agora socialmente considerado como interessante à produção e ao consumo, não é válido e é esquecido. A relação crítica com a tradição é a experiência, da qual abdicamos ao submetermos tudo às leis do mercado, barateando e sucateando assim o que se convencionou chamar de "patrimônio da humanidade", para recebermos em troca, como afirma Benjamim em Experiência e pobreza (1933), a moeda miúda do "atual”.

Se toda reificação é um esquecimento, como afirmaram Adorno e Horkheimer, podemos avaliar o quanto de irracional é o recalque da tradição que se dá tanto na forma do conservadorismo quanto na busca de começar tudo a partir de uma nova racionalidade. Em ambas as posições há o medo da vitalidade do que é morto.

Esse procedimento, que se debruça sobre o longínquo, seja para a cultura material, seja para a consciência, deixando vir à luz a sua vivacidade, atualidade e significação, pode ser comparado à análise que Freud fez dos mecanismos psíquicos do esquecimento.

O esquecimento não seria um lapso qualquer. Lapsos de escrita e de fala, esquecimentos, equívocos na ação, lembranças encobridoras de fatos desagradáveis: o texto A Psicopatologia da Vida Cotidiana (1901) é um verdadeiro tratado sobre o que Freud chamou de atos falhos.

Na pesquisa empreendida por ele, uma série de relatos curiosos, bastante comuns e triviais, Freud encontrou sinais abundantes de que uma resistência se opõe à lembrança de impressões aflitivas. Reconheceu que, no tocante à origem das tradições e da história legendária de um povo, é comum observar a meta coletiva de apagar da memória tudo o que seja penoso. Chega a sugerir uma pesquisa cuja hipótese seria "uma completa analo- 
gia entre os modos de formação das tradições de um povo e das lembranças da infância do indivíduo”. (1987, p. 137)

Sabemos como a passagem do indivíduo para a sociedade, da história para a natureza é complicada, seja em Freud, seja na aplicação que se possa fazer da psicanálise. Freud faz um paralelo entre esquecimento e sofrimento. Esquecer para não sofrer, eis a meta. O dito popular, certamente, antes de qualquer formulação teórica sobre isso, adverte: "Lembrar é sofrer duas vezes".

Ao discorrer sobre o narrador - em processo de desaparecimento, tal como a experiência - Benjamin nos fala do afastamento necessário para olharmos a incomensurabilidade do que se distanciou de nós no espaço e no tempo:

Observados com certo afastamento, os traços fortes e simples, que constituem o narrador, nele preponderam. Melhor: nele se evidenciam da mesma maneira como num rochedo pode surgir uma cabeça humana ou um corpo de animal para o observador que mantém a distância certa e o ângulo de visão correto. (1983, p. 57)

Aqui não há nenhum apelo irracional. Essa racionalidade que se aproxima da tradição, afastando-se dela, procura aguçar o olhar, a escuta, o tato, o olfato, o paladar: a linguagem expressa e sentida pelo corpo.

Se bem observarmos, podemos constatar que as lembranças de infância quase sempre são desencadeadas por odores de lugares, pessoas, objetos. Interessante como a perda da tradição também é a perda da capacidade sensorial ou da nossa possibilidade de lidar com ela. Relevante seria uma pesquisa sobre como se articulam, em nosso cotidiano, a incapacidade de sentir e expressar a linguagem do corpo e as relações antinômicas que temos com a tradição. Já que essa linguagem pode trazer ameaçadoramente à tona, situações petrificantes, há muito petrificadas...

Benjamin faz a distinção entre Erfahrung (experiência) e Erlebnis (vivência), em si mesma, atrofia da experiência substituída como forma de sensibilidade coletiva. O capitalismo com suas formas de trabalho alienado, 
por meio de uma ciência que exige a alienação do corpóreo e o esquecimento do passado, é marcado pela progressiva extinção da experiência. O homem comum não tem energias livres para a reflexão por ter de acionar dispositivos de defesa para suportar esse ambiente de massacre da subjetividade, no qual, em primeira instância, a sobrevivência física está em jogo. O indivíduo está diariamente exposto aos choques da multidão, abrindo caminhos convulsivamente. De outra forma, a cidade não seria transitável: "a sobrevivência na cidade, exige uma atenção super-aguçada, a fim de afastar as ameaças a que está sujeito o passante" (Rouanet, 1981, p. 46).

Mas recuperar, nostalgicamente, o mundo pré-capitalista não é via garantida de emancipação. A Erfahrung tem como base a memória não como restauração épica de uma continuidade perfeita entre passado e presente. A consciência histórica libertadora "explodiria o 'continuum' da história", nas palavras de Benjamin, dando fim a uma pré-história: a história da práxis ilusória definida até hoje pelo domínio da natureza.

Experiência é uma idéia central para Adorno e Benjamin, justamente porque ela já não se verifica na realidade. Raramente, em seus textos, eles se põem a defini-la. Como é de praxe, apontam para o que não é para que o vir a ser possa ser pensado. Mas é possível apreender que a experiência está na contramão da reificação.

\section{A perspectiva do caderno de História dos PCNs}

O caderno de História dos PCNs destaca a contribuição que o ensino de história dá à formação social do estudante e coloca essa formação como um dos mais relevantes objetivos desse ensino. Para que o estudante possa estabelecer relações entre identidades individuais, sociais e coletivas, o caderno dos PCNs aponta para necessidade de desenvolver as noções de diferença, de semelhança, de transformação e permanência:

O domínio das noções de diferença, de semelhança, de transformação e de permanência possibilita ao aluno comparar situações e estabelecer relações e, nesse processo comparativo e relacional, aumentar o seu conhecimento sobre si mesmo, seu grupo, sua região, seu país, o mundo e outras formas de 
viver e outras práticas sociais, culturais, políticas e econômicas construídas por diferentes povos. As atividades escolares com essas noções também evidenciam para o aluno as dimensões da história enquanto conhecimento, experiência e prática social. (p. 16)

A necessidade de um ensino de história que não perca de vista a complexidade das várias temporalidades que indivíduos e sociedades produzem aparece em ainda em diversos trechos do caderno de História dos PCNs dos quais destaco o seguinte:

Os eventos históricos eram tradicionalmente apresentados por autores de modo isolado, deslocados de contextos mais amplos, como muitas vezes ocorria com a história política, em que se destacavam apenas ações de governantes e heróis. Hoje prevalece a ênfase nas relações de complementariedade, continuidade, descontinuidade, circularidade, contradição e tensão com outros fatos de uma época e de outras épocas. Destacam-se eventos que pertencem à vida política, econômica, social e cultural e também aqueles relacionados à dimensão artística, religiosa, familiar, arquitetônica, científica, tecnológica.Valorizam-se eventos do passado mais próximos e/ou mais distantes no tempo. Há a preocupação com as mudanças e/ou com as permanências na vida das sociedades. (p. 20)

O caderno de História apresenta uma nova abordagem do ensino de História, anteriormente historicista. Essa ênfase no processo comparativo e relacional aparece em contraposição ao ensino historicista de história adotado durante o regime militar. Não podemos nos esquecer que os PCNs surgem a partir da Constituição de 1989, a "Constituição cidadã”.

Os conceitos de diferença e semelhança, transformação e permanência aparecem no caderno de História dos PCNs como tentativa de afinar o ensino de História a diversas situações historicamente determinadas:

a expansão escolar para um público culturalmente diversificado, a intensa relação entre os estudantes e as informações difundidas pelos meios de comunicação de massa, as pesquisas pedagógicas - especialmente da Psicologia Social e Cognitiva - e as propostas educacionais que defendem traba- 
lhos de natureza interdisciplinar são fatores (...) que participam das escolhas dos objetivos, dos métodos e dos conteúdos do ensino de História (pág. 14)

Além dessas demandas sociais e culturais, o caderno de História dos PCNs se coloca no centro do debate da ciência histórica, recusando-se a uma neutralização desse debate. Assim, convivem conflituosamente, no universo da ciência histórica, as tendências historiográficas que priorizam a macro-história (análises políticas de instituições, de líderes governamentas, de partidos, de lutas sociais e de políticas públicas) ou a micro-história (pesquisas que aprofundam e revelam as dimensões da vida cotidiana dos trabalhadores, mulheres, crianças, grupos étnicos, velhos e jovens, das práticas e valores regionais). A micro-história exige uma periodização capaz de revelar as dimensões culturais ou de mentalidade, a longa duração. O caderno de História dos PCNs também procura entrar no debate sobre cultura e civilização. Nesse debate a idéia de uma perspectiva evolucionista da História coloca-se em discussão, ressaltando-se os diversos tempos que convivem ao mesmo tempo.

Esses debates dentro da produção de conhecimentos em História, também, apontam para uma ampliação das fontes documentais:

A investigação histórica passou a considerar a importância da utilização de outras fontes documentais e da distinção entre a realidade e a representação da realidade expressa nas gravuras, desenhos, gráficos, mapas, pinturas, esculturas, fotografias, filmes e discursos orais e escritos. Aperfeiçoou, então, métodos para extrair informações de diferentes naturezas dos vários registros humanos já produzidos, reconhecendo que a comunicação entre os homens, além de escrita, é oral, gestual, figurada, musical e rítmica. (p. 13)

Ou seja, o ensino de História apresentado nos PCNs caminha em direção à valorização da experiência do indivíduo, das práticas sociais e das expressões não escritas, priorizando estudos capazes de iluminar "os significados simbólicos das representações sociais” (p. 12). Ampliar as fontes significa também ampliar os atores sociais e os sujeitos da história: 
De modo geral, pode-se dizer que os fatos históricos remetem para as ações realizadas por indivíduos e pelas coletividades, envolvendo eventos políticos, sociais, econômicos e culturais. No caso dos sujeitos históricos, há trabalhos que valorizam atores individuais, quer sejam lideranças políticas, militares, diplomáticas, intelectuais ou religiosas, quer sejam homens anônimos tomados como exemplos para permitir o entendimento de uma coletividade. Outros trabalhos preocupam-se com sujeitos históricos coletivos, destacando a identidade e/ou a discordância entre grupos sociais. Em ambos os casos, há uma preocupação em relacionar tais atores com valores, modos de viver, pensar e agir. De modo geral, pode-se dizer que os sujeitos históricos são indivíduos, grupos ou classes sociais participantes de acontecimentos de repercussão coletiva e/ou imersos em situações cotidianas na luta por transformações ou permanências. (p. 21)

A diferença, a multiplicidade, a identidade e a alteridade estão no cerne da proposta, como podemos observar nos objetivos gerais da área de história elencados abaixo:

- identificar relações sociais no seu próprio grupo de convívio, na localidade, na região e no país, e outras manifestações estabelecidas em outros tempos e espaços;

- situar acontecimentos históricos e localizá-los em uma multiplicidade de tempos;

- reconhecer que o conhecimento histórico é parte de um conhecimento interdisciplinar;

- compreender que as histórias individuais são partes integrantes de histórias coletivas;

- conhecer e respeitar o modo de vida de diferentes grupos, em diversos tempos e espaços, em suas manifestações culturais, econômicas, políticas e sociais, reconhecendo semelhanças e diferenças entre eles, continuidades e descontinuidades, conflitos e contradições sociais;

- questionar sua realidade, identificando problemas e possíveis soluções, conhecendo formas político-institucionais e organizações da sociedade civil que possibilitem modos de atuação; 
- dominar procedimentos de pesquisa escolar e de produção de texto, aprendendo a observar e colher informações de diferentes paisagens e registros escritos, iconográficos, sonoros e materiais;

- valorizar o patrimônio sociocultural e respeitar a diversidade social, considerando critérios éticos;

- valorizar o direito de cidadania dos indivíduos, dos grupos e dos povos como condição de efetivo fortalecimento da democracia, mantendo-se o respeito às diferenças e a luta contra as desigualdades.

Encontramos, portanto, nos PCNs uma respeitável discussão sobre a importância da experiência do indivíduo e da história como ruptura e continuidade. Mas e no que diz respeito à memória? Os PCNs falam enfaticamente numa multiplicidade de fontes documentais, citando a comunicação oral, gestual, musical, rítmica e figurada. Mas, qual é a concepção de memória e sua relação com a história presente nesse documento?

Nas convivências entre as gerações, nas fotos e lembranças dos antepassados e de outros tempos, crianças e jovens socializam-se, aprendem regras sociais e costumes, agregam valores, projetam o futuro e questionam o tempo. Rádio, livros, enciclopédias, jornais, revistas, televisão, cinema, vídeo e computadores também difundem personagens, fatos, datas, cenários e costumes que instigam meninos e meninas a pensarem sobre diferentes contextos e vivências humanas. Nos Jogos Olímpicos, no centenário do cinema, nos cinqüenta anos da bomba de Hiroshima, nos quinhentos anos da chegada dos europeus à América, nos cem anos de República e da abolição da escravidão, os meios de comunicação reconstituíram com gravuras, textos, comentários, fotografias e filmes, glórias, vitórias, invenções, conflitos que marcaram tais acontecimentos. Os jovens sempre participam, a seu modo, desse trabalho da memória, que sempre recria e interpreta o tempo e a História. (p. 19)

O "trabalho da memória" aparece aqui no contato com a tradição seja pela família, pela escola, pelos meios de comunicação de massa em que sempre se recria e interpreta o tempo e a História. A memória, portanto, revela e produz uma história em constante fluxo. 
A seleção e organização dos conteúdos a serem trabalhados na área de História obedecem a essa filosofia da História. Daí a proposta de se trabalhar por eixos temáticos, a saber: História das Relações Sociais, da Cultura e do Trabalho para o terceiro ciclo e História das Representações e das Relações de Poder para o quarto ciclo. Esses eixos temáticos visam problematizar duas questões fundamentais:

A primeira refere-se aos contatos culturais, inter-relações e confrontos entre grupos, classes, povos, culturas e nações. As lutas sociais de grupos e de classes, que reivindicam respeito às diferenças e igualdades, e as lutas de culturas e de etnias na defesa de seus territórios e de suas identidades são problemas cruciais do mundo de hoje. São importantes temas de estudo, na medida em que buscam a compreensão da diversidade de modos de vida, de culturas e de representações internas das sociedades e das organizações sociais. São historicamente relevantes por possibilitarem estudos sobre trocas, intercâmbios e confrontos que contribuem para as transformações e as permanências históricas. Favorecem a percepção dos conflitos geradores de situações de dominação, discriminação, luta, igualdade e desigualdade... A segunda questão refere-se às grandes transformações políticas e tecnológicas atuais, que têm modificado as relações de trabalho, as relações internacionais e marcado profundamente o modo de vida das populações... Mudou o ritmo de vida, assim como, em outras épocas, outras revoluções tecnológicas interferiram no destino dos povos e da humanidade. Não se pode negar que este tema de estudo remete para questões atuais e históricas, favorecendo a percepção de transformações na relação dos homens entre si, com a natureza e com as formas de apreensão da realidade e do tempo. (p. 25)

Não é visível na formulação dos eixos temáticos a relevância da experiência e da memória individual. As duas grandes questões que esses eixos temáticos visam contemplar relacionam-se a uma compreensão da dinâmica social, sem contudo modificá-la. A partir do eixo temático para o terceiro ciclo o aluno deverá ser capaz de compreender o porque das mudanças e permanências, das igualdades e desigualdades como objeto de estudo mas não de auto-reflexão e de transformação social. A segunda questão, da maneira como foi formulada, apresenta a necessidade da compreensão e da 
adaptação do indivíduo ao tempo ditado pela revolução tecnológica. Lendo essa segunda questão - a percepção das transformações na relação dos homens entre si, com a natureza e com as formas de apreensão da realidade e do tempo - é possível lembrar uma passagem da Infância Berlinense em que Benjamin fala das modificações na vida cotidiana introduzidas pelo telefone:

Nada havia que abrandasse o poder sinistro com que me invadia. Impotente, eu sofria, pois me roubava a noção do tempo e do dever e de meus propósitos, e, igual ao médium, que segue a voz vinda de longe que dele se apodera, eu me rendia à primeira proposta que me chegava através do telefone. (Infância Berlinense, O Telefone, p. 80)

Em que medida o ensino de História pode ajudar o aluno a desenvolver a percepção da espoliação subjetiva e objetiva que ele sofre todos os dias através das relações de trabalho e de produção, quanto sua sensibilidade é obliterada e moldada, que seu tempo lhe é roubado, vivendo sob o fetiche do progresso tecnológico e econômico em detrimento da experiência, da memória e da formação de indivíduos? O caderno de História guarda no cerne do que se apresenta como multiplicidade dos tempos históricos, uma perspectiva emancipatória à medida que propõe mostrar aos alunos os diferentes ritmos de tempo nos diferentes momentos históricos:

Dessa forma, os alunos podem compreender e encarar de modo crítico os valores que predominam na sociedade atual, na qual o ritmo avassalador do relógio, da produção da fábrica, da velocidade da informação e seu processamento pelos computadores, impõe, cultural e economicamente, as dinâmicas e as vivências de crianças, jovens, mulheres, homens e velhos (p. 51).

O caderno de História procura diminuir o fosso que separa a história geral da história do particular quando mostra o desdobramento dos eixos temáticos em temas transversais. A partir dos temas transversais seria possível trabalhar questões como as imagens e os valores em relação ao corpo, relacionados à história da sexualidade, dos tabus coletivos, da organização 
das famílias, das concepções sobre a vida e a morte, das relações entre o homem e a natureza, etc. Mas a proposta se revela muito mais afinada com as teorias globalizantes numa perspectiva da macro-história quando observamos os critérios de avaliação. Segundo esse documento, o professor deverá avaliar se o aluno é capaz de:

- Dimensionar, em diferentes temporalidades, as formas de organização políticas nacionais e internacionais;

- Reconhecer diferenças e semelhanças entre o os confrontos, as lutas sociais e políticas, as guerras e as revoluções, do presente e do passado;

- Reconhecer características da cultura capitalista atual e suas relações com a história mundial nos últimos séculos;

- Reconhecer algumas diferenças, semelhanças, transformações e permanências entre idéias e práticas envolvidas na questão da cidadania, construídas e vividas no presente e no passado. (p. 45)

A problematização da relação entre indivíduo e sociedade só aparece no segundo critério de avaliação mencionado em que o professor deverá verificar se o aluno identifica, em perspectiva histórica, a sua vivência cultural, cotidiana, e se relaciona com o sistema dominante e seus valores. Em nenhum momento do caderno de História dos PCNs fala-se numa relação propriamente conflituosa e dissonante entre a experiência individual e a história mundial. É evidente que a experiência individual não é radicalmente diferente da experiência das coletividades. No entanto, tomar uma pela outra ou apenas generalizar não corresponde à proposta de priorizar os entrelaçamentos entre semelhanças e diferenças, transformações e permanências no processo histórico.

Isso quer dizer que o caderno de História dos PCNs acena com a possibilidade de uma micro-história no ensino fundamental, destaca a experiência do indivíduo e as múltiplas fontes documentais para além da linguagem escrita. No entanto, ao detalhar sobre os conteúdos a serem trabalhados e os critérios de avaliação, todas essas ricas possibilidades são um tanto silenciadas. Mas elas retornam quando trata-se da história oral em que o aluno produz o documento. No item dedicado aos recursos didáticos afirma-se que: 
Alguns documentos podem ser, ainda, criados, como no caso de coletar depoimentos, produzir fotografias, documentar sons e imagens com câmaras de vídeo. Pessoas da localidade podem ser entrevistadas sobre vivências específicas ou sobre suas histórias de vida, solicitadas a lembrar de um evento do passado e/ou incentivadas a explicar, a seu modo, as mudanças ou permanências de costumes (p. 57)

Nesse item da "produção de documentos" há uma pequena observação sobre como entrevistar uma pessoa e como definir o estilo da entrevista. Mas não se fala como é possível utilizar esse material, em que medida ele poderá ser comparado/contraposto às fontes tradicionais. Nesse sentido, parece que a comunicação oral e gestual possível de se apreender nesse tipo de pesquisa histórica resulta numa mera ilustração dos conteúdos trabalhados. Isso significa neutralizar a importância da experiência e da memória do indivíduo colocando-as no contexto escolar como "curiosidades". Acredito que esse tipo de iniciativa no contexto escolar é capaz de mobilizar conhecimentos e reflexões que não só ilustrem os conteúdos trabalhados mas os problematize intensamente.

Há um determinado momento do Caderno de História (p. 59) em que aparece uma importante definição de memória: lembrar, rememorar, recordar, perpetuar, consolidar... e também revelar o que foi esquecido, negado, renunciado, rompido, recusado, silenciado... Mas essa definição não acompanha o conjunto do documento e levar isso a sério permanece como uma promessa não cumprida.

\section{Referências bibliográficas}

ADORNO, T.W. e HORKHEIMER, M. Dialética do Esclarecimento. Rio de Janeiro: Jorge Zahar, 1985.

BENJAMIN, W. Experiência e pobreza. In Magia e Técnica, Arte e Política. Obras escolhidas, vol. I. São Paulo: Ed. Brasiliense, pp. 114-119, 1985 (e). 
Infância em Berlim por volta de 1900. Obras escolhidas, vol. II. 5. ed. São Paulo: Ed. Brasiliense, pp. 71-142, 1995.

Sobre alguns temas em Baudelaire. Obras escolhidas, vol. III. 3. ed. São Paulo: Ed. Brasiliense, 1994, pp. 103-150.

BRASIL, Ministério da Educação, Secretaria de Educação Fundamental. Parâmetros Curriculares Nacionais: terceiro e quarto ciclos do ensino fundamental. Brasília: MEC/SEF, 1997.

FREUD, S. Lembranças encobridoras (1899). Obras completas, vol. III. Rio de Janeiro: Imago Ed., 1976.

Psicopatologia da vida cotidiana (1901). Obras completas, vol. VI. Rio de Janeiro, Imago Ed., 1976

GALZERANI, M. Carolina Bovério. Imagens entrecruzadas de infância e de produção de conhecimento histórico em Walter Benjamin. In: FARIA, A. L. G. et alli (orgs.) Por uma cultura da infância. Campinas, SP: Autores Associados, 2002.

PAZ, Octávio. Sóror Juana Inés de la Cruz: as armadilhas da fé. Trad. Wladir Dupont. São Paulo: Ed. Mandarim, 1998.

ROUANET, S. P. Édipo e o anjo: itinerários freudianos em Walter Benjamin. Rio de Janeiro: Tempo Brasileiro, 1981. 